\title{
Meningitis por Staphylococcus aureus meticilino resistente proveniente de la comunidad. A propósito de un caso
}

\author{
Methicillin resistant Staphylococcus aureus community acquired \\ meningitis. A case report
}

\author{
Dra. Roxana Gabriela Spini ${ }^{a}$ Dra. Verónica Ferraris ${ }^{a}$ Dra. María Patricia Glasman ${ }^{a}$ \\ Dra. Guillermina Orofino ${ }^{a}$, Dra. Alejandra Casanovas ${ }^{b}$ y Dr. Gustavo Debaisi ${ }^{c}$
}

\begin{abstract}
RESUMEN
Las infecciones por Staphylococcus aureus meticilino resistente adquiridas de la comunidad han aumentado su frecuencia. La mayoría se presenta como infección de piel y partes blandas. Las formas invasivas más frecuentes son las osteoarticulares y pleuropulmonares. Este germen es causa poco frecuente de meningitis. Se presenta un caso infrecuente de infección por Staphylococcus aureus meticilino resistente adquirida de la comunidad.

Lactante de 8 meses consulta por irritabilidad y fiebre de 4 días de evolución, con sensorio alternante y abdomen doloroso. Descartándose cuadro quirúrgico, se interna con diagnóstico de sepsis a foco enteral. Los hemocultivos y el cultivo de líquido cefalorraquídeo fueron positivos para Staphylococcus aureus meticilino resistente. Se adecua tratamiento antibiótico y evoluciona favorablemente. Al $7^{\text {mo }}$ día de internación, presenta signos y síntomas neurológicos. En la tomografía computada de alta resolución y en la resonancia magnética, se observan imágenes compatibles con mielitis. El paciente cumple tratamiento endovenoso por 21 días con buena evolución, y se otorga el alta hospitalaria al mes de haberse iniciado el cuadro clínico.

Palabras clave: Staphylococcus aureus adquirido de la comunidad, meningitis, bacteriemia, mielitis.
\end{abstract}

\begin{abstract}
Community-acquired Staphylococcus aureus (CA-SA) infections are becoming more frequent. Most cases present an infection of skin and soft tissue, and the most invasive forms observed are osteoarticular and pleuropulmonary infections. Meningitis is a rare manifestation of Sthapylococcus aureus infections. We describe an unusual case of CA-MRSA infection.

An infant of eight months presented with signs of irritability and 4 days duration fever, with alternating sensory and abdomen pain. Acute abdomen surgery was discarded and hospitalization was decided with diagnosis of sepsis due to probable enteral focus; antibiotics were indicated. Blood cultures
\end{abstract}

a. Clínica Pediátrica.

b. Hematooncología Pediátrica.

c. Unidad de Cuidados Intensivos.

Hospital General de Niños Pedro de Elizalde.

Ciudad Autónoma de Buenos Aires.

Correspondencia:

Dra. Roxana Gabriela Spini: spini_ro@yahoo.com.ar

Conflicto de intereses: ninguno que declarar.

Recibido: 19-2-2014

Aceptado: 11-6-2014 and cerebrospinal fluid culture were positive for MRSA. Sepsis with meningitis by MRSA was diagnosed. On the 7th day of hospitalization the infant presented neurological signs and symptoms. On the resolution computed tomography and the magnetic resonance, images compatible with myelitis were observed. The patient complied with the 21 day endovenous treatment, and showed positive results, being discharged from hospital a month after the appearance of the symptoms.

Key words: Community-acquired, Staphylococcus aureus, meningitis, bacteremia, myelitis.

http:/ /dx.doi.org/10.5546/aap.2014.e266

\section{INTRODUCCIÓN}

Las infecciones por Staphylococcus aureus adquiridas de la comunidad (SA-AC) son cada vez más frecuentes. En los últimos años, se ha observado su incremento a expensas del Staphylococcus aureus meticilino resistente proveniente de la comunidad (SAMR-AC). Sin embargo, permanece como una causa poco frecuente de meningitis.

Se destaca en las infecciones por dicho microorganismo la ausencia de factores de riesgo clásicos para SAMR intrahospitalario.

Presentamos a un niño de 8 meses, previamente sano, quien presentó mielitis como complicación de meningitis por SAMR-AC.

\section{CASO CLÍNICO}

Paciente de 8 meses, previamente sano, que consulta por irritabilidad y fiebre de 4 días de evolución. Al momento del ingreso, se constata sensorio alternante más abdomen distendido y doloroso. Se interpreta como sepsis a foco enteral, se descarta cuadro quirúrgico por servicio de cirugía y se decide su internación y tratamiento con ceftriaxona ( $100 \mathrm{mg} / \mathrm{kg} /$ día) y metronidazol (30 mg/kg/día), previa toma de hemocultivos, urocultivo y punción lumbar (traumática).

El paciente permanece en regular estado general y febril. Evoluciona desfavorablemente y presenta a las $48 \mathrm{~h}$ shock séptico, por lo que pasa a cuidados intensivos. Se realiza hemograma: leucocitos, $24300 / \mathrm{mm}^{3}$ (neutrófilos, 77\%); hemoglobina, 9,4 g/L; hematocrito, $27 \%$. 
Plaquetas, $510000 / \mathrm{mm}^{3}$. Se reciben resultados de dos hemocultivos positivos para SAMR (resistente a oxacilina) y, dado el cuadro clínico del paciente, se realiza nueva punción lumbar (citoquímico: xantocrómico; $\mathrm{pH}$ : 8,5; albúmina: 2,2; glucorraquia: 49 (para glucemia: 110); densidad: 1015; láctico: 3,6; elementos: 2900 a predominio PMN. Cultivo: positivo para SAMR, igual sensibilidad).

Se reinterpreta el diagnóstico como sepsis de la comunidad con meningitis por SAMR y se rota antibioticoterapia con vancomicina a $60 \mathrm{mg} / \mathrm{kg} /$ día más rifampicina a $20 \mathrm{mg} / \mathrm{kg} /$ día. Se realiza vancocinemia en pico y en valle, y se ajusta la dosis según los valores terapéuticos. Se descartan otros focos profundos mediante ecocardiograma, fondo de ojos y ecografía abdominal, los cuales se informan como normales.

Se solicita inmunoglobulinas G, A, M y E (dentro de límites normales) y serología VIH (no reactivo) para evaluar inmunidad, dada la mala evolución clínica.

El paciente evoluciona favorablemente. Al séptimo día de internación, presenta paresia de miembros superiores, hiperreflexia de miembros inferiores, signo de Babinsky, clonus y falta de sostén cefálico, con sensorio, sensibilidad y trofismo conservados. En la tomografía computada de alta resolución, se visualiza en cortes inferiores (C1-C2) sin contraste endovenoso imagen difusa en el espacio subaracnoideo que no permite delimitar la médula, con realce difuso de las meninges con contraste endovenoso, más hipodensidad medular y perimedular. En la resonancia magnética de columna con gadolinio, se observa entre C3-C5 medula espinal ensanchada con bordes imprecisos e hiperintensidad en T2, que impresiona de naturaleza inflamatoria, y espacios subaracnoideos obliterados. Se realiza interconsulta con Neurocirugía, que indica pulsos de metilprednisolona por tres días por considerarse mielitis de causa inflamatoria.

El paciente cumple tratamiento antibiótico endovenoso con vancomicina (60 mg/ $\mathrm{kg} /$ día) y rifampicina $(20 \mathrm{mg} / \mathrm{kg} /$ día $)$ por 21 días, con respuesta favorable. Se otorga egreso hospitalario al mes de haberse iniciado el cuadro clínico, con mejoría neurológica y seguimiento por servicios de Infectología, Kinesiología, Neurología y Neurocirugía.

\section{DISCUSIÓN}

Las infecciones por SA-AC son cada vez más frecuentes. En los últimos años, se observa que su incremento es a expensas del SAMR-AC. ${ }^{1-3}$

En Argentina, existen varios reportes sobre infecciones por Staphylococcus: Paganini y colaboradores realizaron un estudio multicéntrico en diferentes hospitales de Argentina entre 2006 y 2007. Se aisló Staphylococcus aureus (SA) en 447 pacientes; 281 (62\%) correspondieron a SAMRAC. La mayoría de los casos se presentó como una infección de piel y partes blandas, y las infecciones osteoarticulares y pleuropulmonares fueron las formas invasivas más frecuentemente observadas. $^{3}$

Además, Paganini y colaboradores realizaron un estudio retrospectivo de todas las bacteriemias por SA diagnosticadas en un hospital pediátrico durante dos períodos (1993-2004 y 2004-2007) y observaron que la frecuencia de infecciones de la piel asociadas a la bacteriemia fue mayor en el segundo período, en el que ya existía incremento de las cepas meticilino resistentes. ${ }^{4}$ El SAMRAC muestra un patrón de sensibilidad diferente del de las cepas de origen hospitalario; las cepas SAMR-AC solo presentan resistencia a meticilina, con variable sensibilidad a clindamicina y baja resistencia a trimetroprima-sulfametoxazol (TMS) en la mayoría de los casos. ${ }^{3,5}$

Otra característica clínica distintiva en estas infecciones es la ausencia de los factores de riesgo clásicamente descritos para la adquisición de SAMR hospitalario, tales como internación, cirugía, uso previo de antibióticos o contacto con personal de salud, por lo que se asemeja al Staphylococcus aureus meticilino sensible de la comunidad (SAMS-AC). Es así que en más del $90 \%$ de los casos no se reconoce factor predisponente alguno para padecer una infección por SAMR-AC,,$^{1,5-7}$ por lo que no hay ninguna recomendación establecida para la búsqueda de dichos factores.

A pesar de este aumento en su incidencia, este germen se mantiene como una causa poco frecuente de meningitis y representa entre 1 y el $9 \%{ }^{1,5}$ En la mayoría de los casos, el mecanismo por el cual se produce la infєcción meníngea sería la diseminación hematugena a partir de focos infecciosos alejados, como osteomielitis, artritis, neumonía o endocarditis. Aunque algunas veces surge de una extensión local al espacio subaracnoideo. ${ }^{5}$

El diagnóstico de la infección se hace mediante el aislamiento de SA en líquidos orgánicos (sangre, orina, material purulento, LCR, etc.).

El tratamiento recomendado por la Infectious Diseases Society of America para la meningitis por SAMR es vancomicina endovenosa por 14 
días. La dosis adecuada para niños no está bien estudiada. Se recomiendan $15 \mathrm{mg} / \mathrm{kg} /$ dosis cada $6 \mathrm{~h}$ para el tratamiento de enfermedad grave o invasiva. Algunos expertos recomiendan agregar rifampicina a $600 \mathrm{mg} /$ día o $300-450 \mathrm{mg}$, 2 veces por día. Como alternativa, se incluyen linezolid a 600 mg vía oral o endovenosa, 2 veces por día, o TMS a $5 \mathrm{mg} / \mathrm{kg} /$ dosis endovenoso cada 8-12 h., ${ }^{2,8}$

Analizando la relación entre la toxicidad de la vancomicina y la dosis administrada, se observa que el desarrollo de nefrotoxicidad es más frecuentes en aquellos tratados con dosis $\geq 4 \mathrm{~g}$ /día. Por lo cual se sugiere limitar el empleo de altas dosis de vancomicina al inicio del tratamiento y, 48-72 h después, es necesario comprobar la concentración sérica de vancomicina en el valle y ajustar las dosis siguientes para obtener los valores deseados.?

El pronóstico es bueno en comparación con los adultos. En varios estudios, se observa un rango de mortalidad entre 14 y $77 \%$. No obstante, la infección adquirida en la comunidad es más grave que la forma intrahospitalaria, la cual se asocia generalmente a un pronóstico favorable y a una tasa relativamente más baja de mortalidad. ${ }^{1}$

En cuanto a las complicaciones, las meningitis bacterianas rara vez se complican con afectación de la médula espinal y, de acuerdo con la literatura revisada, los niños son los que más se afectan. El compromiso medular puede ser debido a compresión por un absceso espinal o por isquemia debido a vasculitis, shock, herniación, aracnoiditis o mielitis. ${ }^{6}$ La prevalencia de mielitis transversa aguda por SA como complicación es rara. La mayoría de las veces ocurre como consecuencia de una diseminación hematógena a partir de otro sitio de infección, como pulmonar, cardíaco, esquelético, gastrointestinal o cutáneo.

Hay estudios en los cuales se observó la presencia de marcados signos de irritación meníngea asociados a dolor abdominal, con conservación del nivel de conciencia en el $40 \%$ de los pacientes que presentaron meningitis por SA.
Debido a que SA presenta múltiples infecciones de localización más frecuentes que meningitis, es razonable pensar que, cuando la meningitis se produce por SA, presenta un trofismo por la médula espinal y produce rigidez de nuca y dolor abdominal. Ambos son causados por un proceso inflamatorio de los nervios espinales con preservación del nivel de conciencia. ${ }^{1}$

Finalmente, dada la prevalencia de la infecciones por SA-AC, en niños con bacteriemia y síntomas meníngeos, siempre hay que tener en cuenta el $S A$ como posible agente etiológico. Nuestro paciente presentó una evolución tórpida de bacteriemia por SAMR, con meningitis y posterior mielitis como complicación de infección por SAMR-AC.

\section{REFERENCIAS}

1. Rodrígues MM,PatrocinioSJ, Rodrigues MG.Staphylococcus aureus meningitis in children: a review of 30 communityadquired cases. Arq Neuropsiquiatr 2000;58(3B):843-51.

2. Paganini H.Staphylococcus aureus. En: Infectología Pediátrica. $1^{\text {ra }}$ ed. Buenos Aires: Científica Interamericana; 2007. Págs.955-61.

3. Paganini H, Della Latta MP, Muller Opet B, Ezcurra G, et al. Estudio multicéntrico sobre las infecciones pediátricas por Staphylococcus aureus meticilino-resistente provenientes de la comunidad en la Argentina. Arch Argent Pediatr 2008;106(5):397-403.

4. Paganini HR, Della Latta P, Soto A, Casimir L, et al. Bacteriemias por Staphylococcus aureus adquiridas en la comunidad: 17 años de experiencia en niños dela Argentina. Arch Argent Pediatr 2010;108(4):311-7.

5. Tagliaferri $P$, von Specht M, Grenon S. Infección meníngea por Staphylococcus aureus resistente a la meticilina adquirido en la comunidad. Arch Argent Pediatr 2006;104(4):354-7.

6. DeSchryver N, Cosnard G, van Pesch V, Godfraind C, et al. ExtensiveSpinal Cord Injury following Staphylococcus aureus Septicemia and Meningitis. Case Rep Neurol 2011;3(2):14753.

7. Mensa J, Barberán J, Llinares P, Picazo JJ, et al. Guía de tratamiento de la infección producida por Staphylococcus aureus resistente a meticilina. Rev Esp Quimioter 2008;21(4):234-58.

8. LiuC, Bayer A, CosgroveSE, Daum RS, et al. Clinical practice guidelines by the Infectious Diseases Society of America for the treatment of methicillin-resistant Staphylococcus aureus infections in adults and children. Clin Infect Dis 2011;52(3):e18-55. 